Michèle Hudon, EBSI, Université de Montréal Laure Amélie Guitard, EBSI, Université de Montréal

\title{
KO and classification instruction objectives: Are we keeping up with the transformation of our field?
}

\begin{abstract}
Each objective listed in courses entirely or partially dedicated to knowledge organization (KO) and bibliographic classification in 30 distinct LIS programs was categorized as to: 1 . its nature; 2. its subject; 3 . its focus; 4. its taxonomic level. The results tend to reinforce observations made over the past 30 years in relation to KO and classification courses. Teaching and learning objectives tend to be very general, with a clearly dominant theoretical focus. Few objectives focus specifically on the complex process of analyzing subjects, and on new types of skills now required to work with classification structures available in digital form. And even if KO educators recognize the necessity for students to develop high-level analytic and evaluative skills, there are very few references to those skills in current course objectives.
\end{abstract}

\section{Background}

Library and information science (LIS) programs are evolving constantly, having to stay up to date with changes in users' needs and behaviors, types and formats of information sources, information technology, and this amidst growing economic pressures. For LIS educators, it is difficult to distinguish the essential from the dispensable, to determine what could be weeded when new content must be added, to link history and tradition to the present and future of the profession their students are about to enter. Educators know that changes in context, systems, practices, and needs will necessarily impact teaching objectives and methods.

Cataloging and classification were at the core of the very first librarians' training programs. Well over a century later, it is remarkable that they still appear as core subjects in most LIS schools, although the terms cataloging and classification themselves appear less frequently in course titles. Combinations of words including information, knowledge, organization and access are now used in a majority of core course titles in which cataloging, classification and indexing are introduced (Joudrey 2008). Topics covered in knowledge and/or information organization courses may include also encoding standards, metadata, taxonomies, ontologies, and folksonomies.

In the past 25 years, cataloging and classification education has been at the core of several research projects. Joudrey (2008), Pattuelli (2010) and Hudon (2010), among others, published extensive reviews of research and literature in the area, covering roughly the period 1985-2010. This period saw the development of the Internet and the implementation of the Web, an exponential increase in the number of digital resources, and the substitution of traditional bibliographic data by various types of metadata. These phenomena created new needs and expectations from employers with regards to what newly graduated LIS professionals should know and be able to do.

Our own interest in the importance given to bibliographic classification in LIS programs, and in best practices in classification education, led to of series of small research projects in the area. One of our goals was to examine whether classification education had evolved over the past 25 years, to reflect major technological changes in the field, as well as the modernization of the LIS curriculum. 
Our first project consisted in a review of the literature on cataloging and classification education published between 1990 and 2010. Our analysis of the literature uncovered eight recurrent themes: history, the place of cataloging and classification in the LIS curriculum, the theory versus practice debate, general course content, specific systems and topics, teaching methods and tools, teaching with online tools, and learning outcomes assessment (Hudon 2010). We identified four areas in need of further investigation: the specific objectives of classification education, the two, and potentially three, dimensions of classification education (the analytical, technical, and technological dimensions), the search for more effective ways of evaluating outcomes, the difficulties of teaching with online versions of classification systems.

A second project allowed us to obtain information from classification instructors in the then 56 ALA-accredited LIS schools in Canada and the United States. Data was collected at the beginning of 2011 by means of a Web-based questionnaire. The survey was structured around issues touching several dimensions of any teaching endeavour, as well as issues concerning more specifically bibliographic classification instruction. The data showed that classification is still an important subject in LIS masters' programs, where it is introduced in core, mandatory organization courses, and often covered with more depth in elective, advanced level courses (Hudon 2011). Specific course objectives were not analyzed in this second study. It is of interest to note that, at the same time, Pattuelli (2010) also examined knowledge organization (KO) courses, analyzing the content of readings lists to determine what was being taught; her study did not consider course objectives either.

\section{Looking at course objectives}

Towards the end of the $20^{\text {th }}$ century, educators were so busy integrating new document types and formats, new technologies, new standards, etc. to the content of their cataloging and classification courses, that they may have lost sight of what it was exactly they were supposed to teach, and more importantly, why. In 1995, MacLeod and Callahan deplored "the educators' lack of a common and coherent description of the chief objectives of cataloging [and classification] education" (163).

With this in mind, the goal of our third research project was to examine general and specific objectives set by educators in current LIS courses entirely or partially dedicated to $\mathrm{KO}$ in general, and to bibliographic classification more specifically. We wanted to determine if and how the necessity for students to understand the basic principles and purposes of $\mathrm{KO}$ and of the classification process, and to acquire multiple sets of practical skills, was clearly reflected in course objectives.

The education theorist Ralph Tyler was among the first, in 1949, to insist on the necessity for educators to set clear objectives; he suggested that objectives should identify "both the kind of behavior to be developed in the student and the content or area of life in which this behavior [was] to operate" (quoted in Toohey 1999, 134). The need for objectives, the types of objectives, and the words with which objectives should be written have since been at the heart of much debate among educators.

Course objectives are essential. They compel instructors to think about what they want students to achieve, and to formulate their expectations in a way which also makes it clear to the students themselves (Toohey 1999, 137). The instructor who has established clear objectives can design relevant and productive teaching and learning 
activities. And when teacher and students know what the outcomes should be, they also know what must/will be evaluated, and how. Ideally, course objectives, teaching methods and assessment methods and tools will be in perfect harmony.

In a professional field such as LIS, objectives are also invaluable to future employers who, knowing what course and program objectives are, and what is expected of students, can adjust their own expectations and requirements accordingly.

Course outlines include two types of objectives. Teaching objectives ${ }^{1}$ specify the intentions of the instructor. They are abstract, subject to interpretation. They describe in general terms the changes expected to happen in students during the course. Teaching objectives most often start with the words: The goals of this course are, followed by expressions such as to provide students with..., to enable students to..., to promote in students..., to introduce students to... Learning objectives are concrete, less subject to interpretation. They start with the words: At the end of this course, the student will be able to, followed by one or two verbs such as understand, appreciate, describe, identify, solve, design, and an object expressed in the form of a noun. Learning objectives, on the contrary, adopt the students' point of view, and emphasize what they are to achieve rather than what the instructor plans to do or what topics will be covered in the course. Learning objectives are normally more precise than teaching objectives, and they often refer to a specific learning situation and element of content. In our corpus, a typical example of a teaching objective was: To acquaint students with methods of creating and providing access to records. An example of a learning objective was: The student will be able to identify appropriate approaches to the organization of information materials and resources in various situations and environments.

Learning objectives can be ranked on the basis of the complexity of the cognitive processes required to achieve them. Benjamin S. Bloom's taxonomy (1956), a scale progressing from the concrete (less complex) to the abstract (more complex) is among the best known and the most widely used tool applied to the categorization of learning objectives. Blooms' former student L.W. Anderson, with D. Krathwohl, has revised the taxonomy in the 1990s, inverting levels 5 and 6 and replacing by verbs all noun forms used in the original (e.g. Knowledge became Remembering, Comprehension became Understanding) (Overbaugh and Schultz, undated Web document). In this project, we used the Anderson and Krathwohl's modification.

\section{Method}

\section{Data collection}

The Web sites of all ALA-accredited LIS schools were examined to identify core and elective courses entirely or partially dedicated to $\mathrm{KO}$, and to bibliographic classification more specifically. A search for course outlines was conducted. Instructors' personal or institutional Web sites were explored when needed. Several outlines which could not be found or were not publicly accessible on the Web were obtained through direct requests to course instructors.

We encountered several cases of duplicate courses, i.e. courses offered, simultaneously or not, to different groups of students by the same or by different instructors. Duplicate courses also included those courses offered, simultaneously or

\footnotetext{
${ }^{1}$ In our research and in this paper, we use the terms Teaching and Learning objectives instead of the terms General and Specific objectives often encountered in the literature of Education.
} 
not, in different formats (e.g. online and in-class) by the same or by different instructors. Duplicate courses were treated as a single course if teaching and learning objectives were identical, and as distinct courses if objectives were different.

We originally collected outlines of courses dedicated to indexing and abstracting, but these were eventually left out when it could be ascertained that the objectives set in those courses were too specific for our purposes. Metadata course outlines were also originally collected, but we found their objectives and the description of their contents to be often vague and ambiguous. Few of those courses were ultimately considered in our analysis; those that were considered made it clear that they were not strictly technically-oriented and that they were presenting traditional organization standards as well as more recently created ones.

Preparation of data

We transferred on a spreadsheet the content of all sections titled Goals, Objectives, Course objectives, General objectives, Specific objectives, Learning objectives, and Learning outcomes. If no such section was available in a course outline, we used the general course description, where objectives were sometimes included within an introductory text. Sentences which listed more than one measureable objectives (e.g. $\underline{B e}$ $\underline{\text { able to }}$ recognize and describe different types of classification schemes and controlled vocabularies) were split.

Coding

Each objective was categorized along four dimensions: 1. its nature (Teaching objective / Learning objective); 2. its subject (General KO, Descriptive cataloguing, Access/Subject access, Classification/Classification schemes, Indexing/Indexing languages, Other); 3. its focus (Theoretical, Analytical, Technical/Application, Technological/Interface, Other); and 4. its level, along the continuum proposed by Bloom and revised by Anderson and Krathwohl (Remembering, Understanding, Applying, Analyzing, Evaluating, Creating). Verbs were used to determine the nature and the taxonomic level of each objective, while nouns helped to identify subject and focus.

\section{Results and discussions}

General characteristics of the corpus

Sixty-three course outlines were available for analysis; they described courses offered most recently in the period starting in the Fall term of 2011 and ending in the Spring term of 2013. Twenty-seven courses were core courses, offered at least once every year to all students in a LIS program; thirty-six courses were electives. Thirty of the 62 currently ALA-accredited LIS programs in Canada and the United States were represented; several distinct course outlines were available for 21 programs.

We were not surprised to observe that twenty-six course titles are formed by a combination of the words information, knowledge, and organization (e.g. Information and knowledge organization, Organization of information, Information organization and access in context); six of these only are not core courses. The words cataloging and classification appear in 19 course titles (e.g. Basic cataloging and classification, Advanced classification and cataloging); only three of these are core courses. 
Our unit for analysis was the single objective. A total of 458 discrete objectives were analyzed and coded. The smallest number of objectives available for analysis in a single course was three; the highest number of objectives was 17. Each objective was coded on the basis of its wording only.

Nature of the objectives

Four hundred objectives were coded as learning objectives, and 58 only as general teaching objectives. Of the 12 course outlines which list teaching objectives, five propose only this type of objective, and four of these five courses are core courses. These numbers can be seen in a positive light since it may indicate that $\mathrm{KO}$ and classification instructors increasingly adopt a learner- rather than a teacher-centered approach. As learning objectives are normally more specific and less open to interpretation than teaching objectives, we suggest that it is easier for students and for prospective employers to know which elements of knowledge and which skills will have been acquired and developed in $\mathrm{KO}$ and classification courses upon graduation.

Subject of the objectives

Significant nouns or noun phrases, and occasionally verbal forms, were used to determine the main subject of an objective (Table 1). Many objectives addressed more than one subject (e.g. To place the activities of classification and indexing within a broader perspective of human intellectual activity).

Table 1Nouns used to categorize the main subject of objectives

\begin{tabular}{cl}
\hline General KO & $\begin{array}{l}\text { bibliographic control // bibliographic organization // information architecture // } \\
\text { organization of information / knowledge // organizational structures }\end{array}$ \\
\hline Descriptive & AACR2 // authority control // descriptive cataloging // RDA \\
\hline Access & $\begin{array}{l}\text { access to information // information retrieval // intellectual access to information // user } \\
\text { access }\end{array}$ \\
\hline Classification & $\begin{array}{l}\text { categorization // classification // classification schemes // classificatory structures // } \\
\text { DDC // LCC // subject classification }\end{array}$ \\
\hline Indexing & \begin{tabular}{l} 
controlled vocabulary // indexing // LCSH // subject headings // thesaurus \\
\hline Other
\end{tabular} \\
\hline $\begin{array}{l}\text { Bibliographic utilities // database design // document (nature of) // electronic systems // } \\
\text { information (nature of) // information needs // interoperability // metadata schemes // } \\
\text { technical services // usability }\end{array}$ \\
\hline
\end{tabular}

Were categorized as General $\mathrm{KO}$ all objectives referring in general terms to information and/or knowledge organization (e.g. Introduce the theory, principles, standards, and methods for knowledge organization), as well as objectives referring to more than two subjects and which could have been categorized in more than two categories (e.g. To give in-depth coverage of cataloging tools, including AACR $2 R$, $L C S H, L C C$, and MARC21 formats). Objectives which referred to two distinct subjects were placed in the appropriate categories (e.g. To describe the principles of cataloging and classification was classified in both Descriptive and Classification categories). The term cataloging, when used on its own, was taken in its general sense as including both descriptive and subject cataloging; it usually led to a placement in the General KO category (e.g. Become familiar with the terminology and jargon of library cataloging); 
when used in combination with either classification or indexing, the term cataloging was given the narrower meaning of descriptive cataloging (e.g. To understand basic principles of cataloging and classification that have developed over the last century was classified in both Descriptive and Classification categories).

The Other category received objectives whose main subject is not one of the operations or tools associated directly with $\mathrm{KO}$ or classification. Most frequently found in this category are objectives relating to the concepts of information or document (e.g. To understand the basic nature of documents), to users and their needs (e.g. To understand the relationship between information needs and the universe of available resources), to databases and retrieval systems (e.g. To analyze search tools, web sites, and other information management products), to technical services management (e.g. To understand the technical services practice and potential changes in libraries). Were also categorized as Other all objectives referring to metadata standards (e.g. To demonstrate basic skills in metadata creation, including basic knowledge of at least two metadata standards (for example MARC and Dublin Core), to the MARC format in general terms (e.g. Be familiar with the MARC format for the manipulation of data), and to general cognitive skills (e.g. To promote critical thinking and problem solving abilities for addressing challenges of organizing information in the digital age).

Table 2 Main subjects in teaching and learning objectives

\begin{tabular}{c|c|c|c|c|c|c} 
& Gen. KO & Descr. & Access & Classif. & Index. & Other \\
\hline \hline Core & 120 & 19 & 8 & 21 & 22 & 68 \\
\hline Elect. & 84 & 44 & 14 & 41 & 38 & 46 \\
\hline Total & 204 & 63 & 22 & 62 & 60 & 114 \\
\hline
\end{tabular}

Table 2 shows that $\mathrm{KO}$ and classification course objectives are general in nature; in core courses, this is to be expected, with a focus now on knowledge and information organization as a field of study and activity, rather than on specific operations such as classification or indexing. In elective courses, however, the number of general objectives remains equivalent to the sum of objectives referring specifically to description and classification; this may have to do with our habit of using the term cataloging quite liberally to designate any operation that will make information and documents accessible and retrievable. The important number of objectives referring to other subjects indicates that $\mathrm{KO}$ and classification courses, even in their advanced form, always attempt to cover a lot of ground. The large number of objectives classified as General KO and as Other (318 out of 525, or 60,5\%) suggests that it could be difficult for instructors to identify and use the most appropriate teaching methods and assessment tools, and for students to know exactly why they take a course and what they will learn.

Focus of the objectives

The focus of the objective represents the nature of the information, knowledge or skills that the student is expected to acquire or develop. Focus was determined by looking at particular combinations of verbs and nouns which suggested if the objective addressed the transfer of theoretical, philosophical or historical knowledge (subsumed under Theory), the analysis and interpretation of a subject (Analysis), the development of 
technical skills (Application), or familiarization with technological tools (Technology). Examples are: To understand the underlying principles of cataloging and classification (Theory), To develop an appreciation for the problematic nature of determining content attributes of information objects, including subject (Analysis), To apply standardized cataloging tools to catalog and classify materials in different format (Application), To develop skills in using WorldCat, WebDewey, Cataloger's Desktop, and ClassWeb (Technology). Were grouped in the Other category those objectives referring to skills indirectly related to $\mathrm{KO}$ and classification, as in To understand administrative issues affecting organization of information, and To understand the technical services practice and potential change in libraries. Several objectives were coded as having two different foci, the most frequent combination being Theory / Application (e.g. To learn the structure and application of the major classification schemes, such as...).

Table 3 Main focus of the teaching and learning objectives

\begin{tabular}{c|c|c|c|c|c} 
& Theory & Analysis & Application & Technology & Other \\
\hline \hline Core & 161 & 6 & 67 & 4 & 4 \\
\hline Elect. & 139 & 10 & 99 & 7 & 6 \\
\hline Total & 300 & 16 & 166 & 11 & 10 \\
\hline
\end{tabular}

In the first of our projects, we had found in the literature a few references to the fact that there were at least two dimensions to be considered when teaching bibliographic classification: the cognitive dimension (subject analysis) and the technical dimension (use of tables, class number building, etc.). With the growing availability and use of classification schemes, list of subject headings, etc. in digital format, we suggested that a new set of skills was now required of students, and that a technological dimension was now also to be considered (Hudon 2010). The categories established to identify focus reflected this suggestion.

Table 3 shows that theory remains largely dominant in both introductory and advanced courses, with technical skills coming in rather far behind. Sixteen objectives only mentioned the cognitive process of subject analysis and 11 made a reference to technological products or interfaces. Because even learning objectives are not necessarily very precise, we realize that these numbers are likely misleading. It is almost certain that instructors who write a technical objective such as The student will be able to classify a document using the DDC means to cover also instruction on and practice of the subject analysis process. It cannot be assumed, however, that the objective also covers the use of a tool such as WebDewey ${ }^{2}$.

Level of the objectives

The level of each one of the 400 learning objectives was categorized according to the Bloom's scale, as modified by Anderson and Krathwohl. Table 4 shows the six levels in the scale; the denomination of each level is given in bold characters, with the original name, chosen by Bloom, in square brackets. The third column lists the most frequent verbs and verbal forms found in our corpus and used for coding to a level.

\footnotetext{
${ }^{2}$ WebDewey is a registered trademark of OCLC.
} 
Table 4 Taxonomy of learning objectives

\begin{tabular}{|c|c|c|}
\hline Level & Taxonomy & Verbs in corpus \\
\hline 6 & $\begin{array}{l}\text { Creating: Can the student create new } \\
\text { product, new point of view? [Synthesis - } \\
\text { Level 5] }\end{array}$ & Create // Design \\
\hline 5 & $\begin{array}{l}\text { Evaluating: Can the student justify a } \\
\text { stand or decision? [Evaluation - Level 6] }\end{array}$ & Assess // Evaluate // Judge \\
\hline 4 & $\begin{array}{l}\text { Analyzing: Can the students distinguish } \\
\text { between tools, etc. [Analysis] }\end{array}$ & $\begin{array}{l}\text { Analyze // Argue // Compare // Contrast // } \\
\text { Critically analyze // Solve (problem) // Speak on } \\
\text { // Synthesize // Write on }\end{array}$ \\
\hline 3 & $\begin{array}{l}\text { Applying: Can the student use } \\
\text { information? [Application] }\end{array}$ & $\begin{array}{l}\text { Apply // Classify (in the LIS sense) Code // } \\
\text { Describe (in the LIS sense) // Do // Encode // } \\
\text { Format // Perform // Select // Use }\end{array}$ \\
\hline 2 & $\begin{array}{l}\text { Understanding: Can the student explain } \\
\text { ideas, describe objects? [Understanding] }\end{array}$ & $\begin{array}{l}\text { Describe // Define (in your own words) // Discuss } \\
\text { // Explain // Illustrate // Interpret // Provide } \\
\text { examples of // Summarize // Understand // }\end{array}$ \\
\hline 1 & $\begin{array}{l}\text { Remembering: Can the student recall or } \\
\text { remember the information? [Knowledge] }\end{array}$ & $\begin{array}{l}\text { be aware of // be familiar with // enumerate // } \\
\text { know / have basic knowledge of // identify // list } \\
\text { // name }\end{array}$ \\
\hline
\end{tabular}

In Table 4, the climbing arrow illustrates the progression in complexity of behavior expected of learners, from the very concrete (acquiring knowledge and skills and applying them) to the abstract (analyzing and producing new knowledge). The double dividing line between levels 3 and 4 separates the concrete from the abstract. It is believed that a good number of objectives established in higher education courses should reach the higher levels of the taxonomy. The knowledge and skills defined at each level of the scale are naturally added to the knowledge and skills defined at all inferior levels; a learner cannot evaluate, for example, if he has not acquired, understood, applied and analyzed the relevant knowledge in a discipline or domain of activity.

Each objective in our corpus was placed in one category/level only. When a single objective was clearly at the junction of two levels, it was placed in the highest of the two.

Table 5 Level of learning objectives

\begin{tabular}{c|c|c|c|c|c|c} 
& Level 1 & Level 2 & Level 3 & Level 4 & Level 5 & Level 6 \\
\hline \hline Core & 21 & 77 & 55 & 18 & 6 & 6 \\
\hline Elect. & 28 & 86 & 85 & 10 & 6 & 2 \\
\hline Total & 49 & 163 & 140 & 28 & 12 & 8 \\
\hline
\end{tabular}

Table 5 shows that the vast majority of objectives proposed in $\mathrm{KO}$ and classification courses (352 out of 400 , or $88 \%$ ) remain squarely in the lower levels of the scale, with 303 objectives written at Level 2 and Level 3. In core courses, this phenomenon does not come as a surprise. LIS masters' students have very diverse academic backgrounds, most of them having little or no experience or even knowledge of the field they are entering; they usually complete the mandatory introductory $\mathrm{KO}$ course at the beginning of their training, and they must be exposed to a wide variety of concepts, principles, tools, and practices. It is more surprising to see that even elective courses, often 
considered "advanced" courses, do not go beyond Level 3. One reason could be that so much now has to be covered in core courses that there is not much room to discuss the basics of classification; instructors are them forced to cover the fundamental knowledge and applications in advanced courses, leaving even there little or no time for deep analysis, evaluation and design. Another possible explanation would be that KO and classification courses remain very "traditional" as to objectives and contents, leaving the more complex operations to be presented in new (and often to the students more attractive) courses, such as Indexing and Indexing languages, Taxonomies, Ontologies, Text analysis, etc.

\section{Challenges and limitations of the study}

There is not a single way of writing learning, or even teaching objectives, and few of us have been taught to do it properly. The goal of this project was not of course to criticize the form of the objectives, but form turned out to have more of an impact than we had anticipated. The ease with which we could code an objective as precise as The student will be able to discuss the theories of subject classification was quickly forgotten when we had to parse vague (e.g. To understand structures, formats and standards), or dense objectives (e.g. After being introduced to the principles and practices of the organization of information, students will critically examine, assess, and make recommendations as to how these concepts and principles are applied in various information environments, including the Web).

We believe that this small-scale project reveals interesting facts about how classification is being taught in the $21^{\text {st }}$ century. However, we are conscious of significant limitations. We had wrongly assumed that a majority of LIS schools Web sites would give access to current course outlines, as a means of promoting their program; of the estimated 100 relevant courses identified in a previous project, 63 only could be considered for this analysis of objectives.

Analysis and coding of all objectives was done first by a research assistant (doctoral candidate), then reviewed twice by the researcher at different times. The first review led to a number of substantial modifications in the coding of Subject and Focus. Less than 50 modifications were made during the second review, which happened several weeks after the first one. A search on specific words (verbs and nouns) was conducted to ensure that the codes associated with these words were consistent. We took great care in our analysis to avoid reading more into an objective than what was actually expressed; we are conscious, however, that our interpretation of complex objectives could not be entirely devoid of subjectivity.

The course objectives were considered independently of their context, which we would define as the place of the course in the program, the description of contents and assignments, the calendar of activities. It is possible that an analysis of objectives "in context" would have revealed, for example, that more practical work would be accomplished during the course than what could be deducted from the wording of the objective. A correlation between objectives, teaching activities and methods for assessing learning outcomes would have revealed whether these were congruent, and if there was an apparent progression in the complexity of the behaviour expected of students. This was not, however, an objective of this project, and this level of analysis was not attempted. 


\section{Conclusion}

The goal of this project was to examine general and specific objectives set by educators in current LIS courses entirely or partially dedicated to $\mathrm{KO}$ in general, and to bibliographic classification more specifically, in ALA-accredited masters' programs. Our aim was to determine if and how the necessity for students to understand the basic principles and purposes of $\mathrm{KO}$ and of the classification process, and to acquire a variety of practical skills, was addressed in objectives set in core and elective courses.

Given the limitations associated with the size of our corpus and with our methodology, no generalization is possible. Tendencies, however, are revealed, and our results tend to reinforce what has been observed over the past 25 years in $\mathrm{KO}$ and classification education.

A significant number of teaching and even learning objectives are very general, and often rather vague, covering in a single sentence many concepts and subjects. In both core and elective courses, the number of objectives which have a theoretical focus remains important. It is significant to note the rarity of objectives focusing on subject analysis (as a cognitive process) or on the use of technology, as if instructors believed that these skills were acquired by instinct or osmosis rather than by actual learning and practice. And, despite the fact that instructors do recognize the necessity for students to develop high-level analytic and evaluative skills, we see very little explicit reference to them in current course objectives.

\section{References}

Bloom, B.S. 1956. Taxonomy of Educational Objectives, Handbook I: The Cognitive Domain. New York: David McKay.

Hudon, M. 2010. Teaching classification, 1990-2010. Cataloging \& Classification Quarterly 48, $1,64-82$.

Hudon, M. 2011. Teaching classification in the $21^{\text {st }}$ century. Knowledge Organization 38, 4, 342 351.

MacLeod, J., and D. Callahan. 1995. Educators and practitioners reply: An assessment of cataloging education. Library Resources \& Technical Services 39, 2, 153-165.

Joudrey, D.N. 2008. Another look at graduate education for cataloging and the organization of information. Cataloging \& Classification Quarterly 46, 2, 137-181.

Overbaugh, R.C., and L. Schultz. Bloom's Taxonomy. Norfolk, VA: Old Dominion University. Online at: http://ww2.odu.edu/educ/roverbau/Bloom/blooms taxonomy.htm (consulted on May 7 2013).

Pattuelli, M.C. 2010. Knowledge organization landscape: A content analysis of introductory courses. Journal of Information Science 36, 6, 812-822.

Toohey, S. 1999. Designing courses for higher education. Buckingham: The Society for Higher Education and Open University Press. 